NOTICE : this is the author's version of a work that was accepted for publication in Carbon. Changes resulting from the publishing process, such as peer review, editing, corrections, structural formatting, and other quality control mechanisms may not be reflected in this document. Changes may have been made to this work since it was submitted for publication. A definitive version was subsequently published in Carbon (2007), doi:10.1016/j.carbon.2007.01.012

\title{
Analyzing the quality of carbon nanotube dispersions in polymers using scanning electron microscopy
}

\author{
Josef Z. Kovacs a, ${ }^{*}$, Kjer Andresen ${ }^{a}$, Jan Roman Pauls ${ }^{a}$, Claudia Pardo Garcia ${ }^{a}$, \\ Michael Schossig ${ }^{\mathrm{b}}$, Karl Schulte ${ }^{\mathrm{c}}$, Wolfgang Bauhofer ${ }^{\mathrm{a}}$ \\ ${ }^{a}$ Institut für Optische und Elektronische Materialien, Technische Universität Hamburg-Harburg, \\ Eissendorfer Strasse 38, D-21073 Hamburg, Germany \\ ${ }^{b}$ Institut für Polymerforschung, GKSS Forschungszentrum Geesthacht GmbH, Kantstrasse 55, \\ D-14513 Teltow, Germany \\ ${ }^{c}$ Institut für Kunststoffe und Verbundwerkstoffe, Technische Universität Hamburg-Harburg, \\ Denickestrasse 15, D-21073 Hamburg, Germany
}

\begin{abstract}
The ability to examine conducting filler particles in an insulating polymer matrix by scanning electron microscopy (SEM) was investigated. The detection of selected secondary electrons is necessary to resolve sub-micron scale filler particles, but not every SEM detector seems to be able to monitor the small changes introduced by the conducting filler particles. The influence of SEM parameters and the challenge of image interpretation in view of the apparent lack of appropriate information in literature are discussed. In accordance with other experiments on light element samples, all monitored electrons seem to be emitted within approximately $50 \mathrm{~nm}$ of the sample depth and no information is accessible from deeper regions even by increasing the acceleration voltage.
\end{abstract}

Keywords: Carbon Nanotubes; Resins; Scanning Electron Microscopy; Electrical (Electronic) Properties

\section{Introduction}

Polymer composites containing nanoscaled filler particles were investigated for decades. However, since the discovery of carbon nanotubes (CNTs) [1-4] the interest is growing considerably. Many theories and explanations on CNT properties and their transfer into the composite thereby rely on assumptions of certain particle shapes and distributions. These assumptions were supported - if at all - by optical micrographs [5-18], atomic force microscopy $[19,20]$, SEM studies restricted to sample surfaces (due to etching, conductive coating or choice of detector) [21-41] and TEM micrographs [42-56].

\footnotetext{
* Corresponding author. Tel.: +49 4042878 3853; Fax: +49 4042878 2229. E-mail address: josef.kovacs@ @uhh.de (J.Z. Kovacs).
} 
TEM usually examines samples on a sub-micron scale, the resolution of optical images $(\sim 0.2 \mu \mathrm{m})$ impedes the visualization of individual nanotubes. All other methods mentioned above analyze merely the surface of a sample. However, SEM on uncoated samples and with the right detector is able to cover nearly all length scales from TEM to light microscopy and simultaneously allows a shallow insight into the sample $[57,58]$. The technique is based on sensing potential variations on the sample surface that were caused by electron charging. This contrast effect was known as early as 1957 [59] and was termed "voltage contrast". A discussion on this technique was conducted by Chung et al. [60] in 1983 who monitored carbon black fillers. It was continued by Loos et al. [61] in 2005 who analyzed carbon nanotubes. Lillehei et al. contributed a NIST practice guide in 2005 on how to characterize the dispersion of carbon nanotubes in a polymer matrix [62]. Voltage contrast images of nanotubes were already published before 2005 [63-67] and also thereafter [68-70], unfortunately without exploring and explaining how to make such images.

The present work intends to supply detailed information on the way how to visualize nanotubes in insulating matrices. Subsequently, the effect of various SEM parameters as well as requirements on sample conductivity and SEM detector type are illustrated by imaging carbon nanotube epoxy composites. The aim of this work is to provide knowledge about this technique to all researchers and to facilitate them to determine real particle shapes and distributions in their samples over several length scales.

\section{Experimental}

Multi-wall carbon nanotubes (MWCNT) grown by catalytic chemical vapor deposition (CCVD) were supplied by Nanocyl S.A. (Belgium) and specified with average inner and outer diameter of 4 and $15 \mathrm{~nm}$, respectively, lengths up to $50 \mu \mathrm{m}$ and carbon purity exceeding $95 \%$ (<5\% iron catalyst). Two bisphenol-A-based epoxy resins, Araldite LY 556 (Huntsman Advanced Materials, Belgium) and Chem Res E20 (Cognis, Germany) along with one amine-based hardener (XB 3473, Huntsman Advanced Materials, Belgium) were kindly provided by the mentioned companies and were used in this work. A polyether siloxane copolymer (Tego Wet 280) obtained from Degussa, Tego Coating \& Ink Additives (Germany) was used as wetting agent for the glass substrates.

Samples containing $0.1-1 \mathrm{wt} \%$ CNT were prepared by mixing epoxy and nanotubes primarily with a dissolver disk (2000 rpm for 2 hours) and then with a three roll calender (5 $\mu \mathrm{m}$ gap size) [71]. The suspension collected from the rolls was filled in small bottles and immediately transferred to a refrigerator to prevent reagglomeration of the CNTs. Hardener (23 wt\%) and wetting agent (1 wt\%) were added to consecutively thermalized bottles, then mixed manually with the suspension (around $2 \mathrm{~g}$ ) and subsequently centrifugated (4000 rpm) or exposed to vacuum (for $1 \mathrm{~h}$ ) to remove the air bubbles. The dispersion was spin-coated onto glass substrates at $5000-9000 \mathrm{rpm}$ for $1 \mathrm{~min}$ using a Convac TSR 48 spin-coater. The samples were cured on a hot-plate or in an oven at 
$120-150^{\circ} \mathrm{C}$ for $6-48$ hours. Film thicknesses were then determined with a Sloan Dektak 3030 ST surface profilometer and ranged between 8 and $30 \mu \mathrm{m}$. Extensive scanning electron microscopy (SEM) analyses were conducted on LEO 1530 FE-SEM using two detectors. One is situated inside the beam focusing lens (called InLens) and monitors only secondary electrons of type $1\left(\mathrm{SE}_{1}\right)[57,58]$ which are attracted by an electrostatic lens field of $8 \mathrm{kV}[72,73]$. The other detector (called Everhart-Thornley, ET) placed beside the specimen and operated with a positive bias of $400 \mathrm{~V}$ is sensitive to both, $\mathrm{SE}_{1}$ and $\mathrm{SE}_{2}$. The films were analyzed without applying surface etching or conductive layer coating techniques. The SEM parameters were as follows: working distance of $2-4 \mathrm{~mm}$, aperture of $20-30 \mu \mathrm{m}$, acceleration voltage of $0.2-20 \mathrm{kV}$, magnification of $500 \times-500,000 \times$ with respect to a $1024 \times 768$ pixel image and scanning speed of $20 \mathrm{sec} /$ frame.
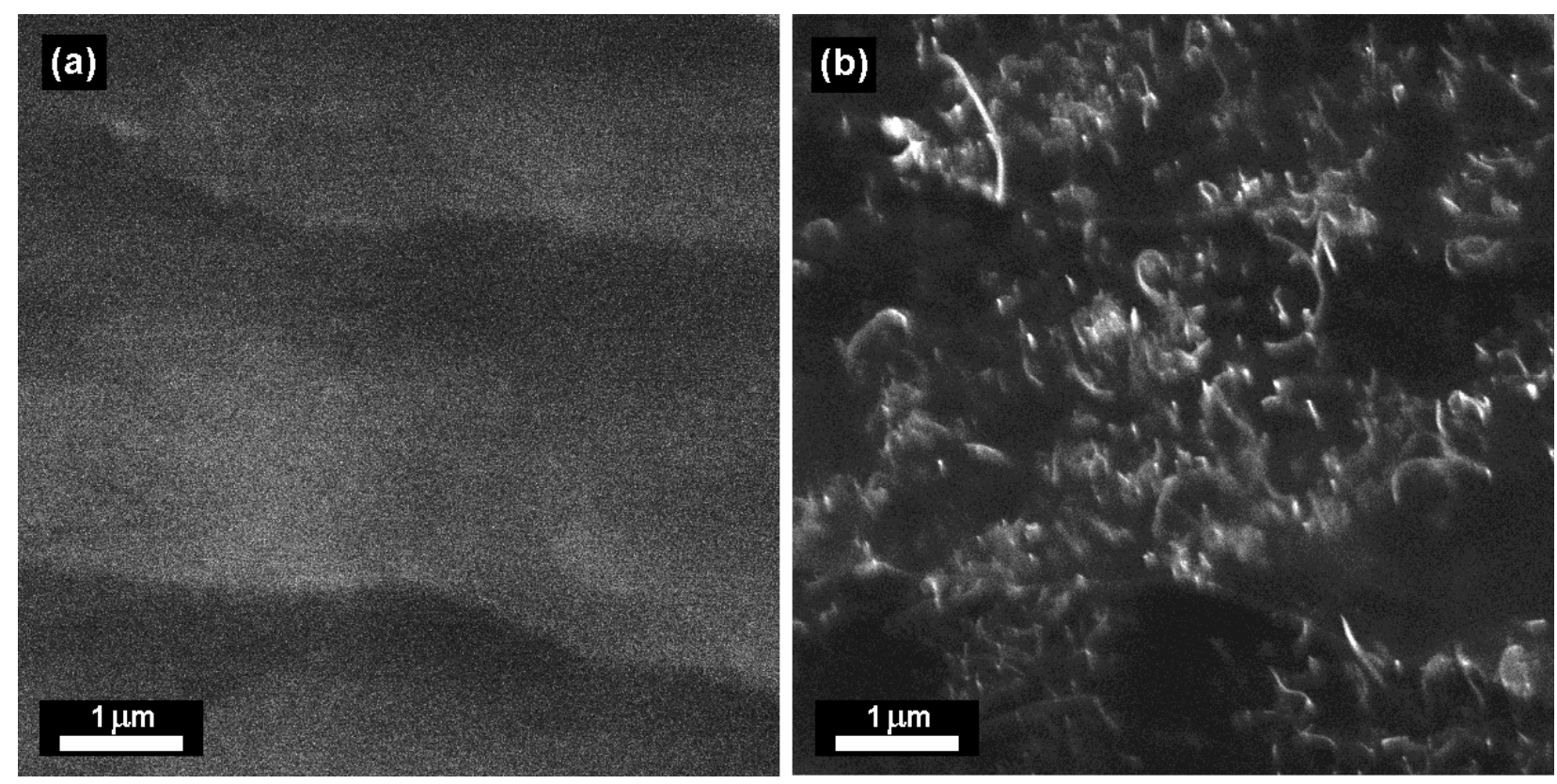

Fig. 1. Cryo fractured surface of a composite of 1 wt\% MWCNTs dispersed in LY556 recorded with (a) the $E T$ detector and (b) the InLens detector at $10 \mathrm{kV}$ acceleration voltage and $25000 \times$ magnification.

\section{Results}

\subsection{Visualization of filler particles inside a polymer matrix}

Fig. 1 presents two SEM images of the same area on a cryo fractured specimen (note the ditches that are visible in both pictures), one image recorded with the ET detector (Fig. 1a) and the other with the InLens detector (Fig. 1b). Bright structures are visible in Fig. $1 \mathrm{~b}$ only and are attributed to nanotubes. Fig. 1a seems to be dominated by topographic contrast, but no nanotubes are visible here, meaning that they are inside the polymer rather than on the surface. It is important to note that the resolution of $\mathrm{SE}_{2}$ at 10 $\mathrm{kV}$ is around $2 \mu \mathrm{m}$ (due to the large electron emission area with radius $\approx 0.6 \mathrm{R}_{\mathrm{kO}}$, where $R_{K O}$ is the Kanaya-Okayama range [57]) while the ditch visible in Fig. 1a is resolved on a sub-micron scale. This means that even with the ET detector we are monitoring mainly 
$S E_{1}$. This is not surprising when considering the $S E_{1}$ to $S E_{2}$ emission ratio in carbon element samples which is 5:1 [57].

But why are nanotubes visible in Fig. 1b and not in Fig. 1a (working distances up to 16 $\mathrm{mm}$ were examined) although $\mathrm{SE}_{1}$ are monitored in both cases? Besides topographic contrast only voltage contrast is present due to potential differences between the insulating polymer and the metallic CNT. This contrast is present in both images, but it seems to influence the $\mathrm{SE}_{1}$ signal recorded by our InLens detector only. Dotan [74] finds the same effect and uses it deliberately to avoid charge influences in the ET signal. However, this does not mean that ET detectors in general are not capable to sense these slight charges on a sample surface, as demonstrated by Loos et al. $[61,66]$ with an Environmental SEM (ESEM) from FEI Company. We were able to take similar images with the ET detector of a JSM-840A SEM from Jeol. The InLens detector from Hitachi SEM devices is also sensitive to voltage contrast $[64,65,69,70]$, but as it works different than ours, it seems to be immune to excessive surface charging at the same time. Thus, as long as the electric field influence for new detector (InLens) or microscope types (ESEM, LVSEM) are not explored, attention has to be paid to the choice of the detector [75].
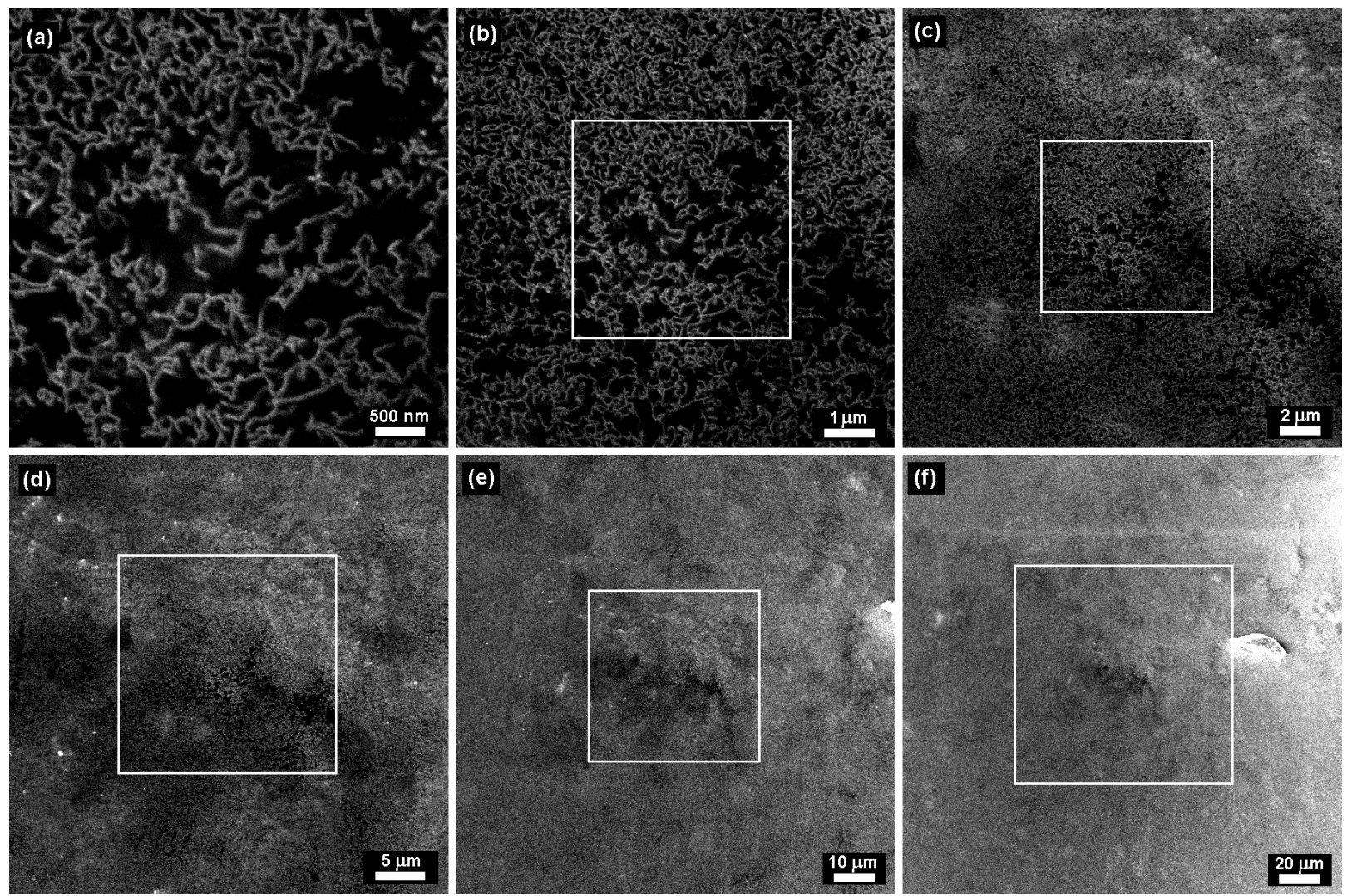

Fig. 2. Spin-coated composite (14 $\mu \mathrm{m}$ film thickness) containing 1 wt\% MWCNTs in E20 resin recorded at $10 \mathrm{kV}$ acceleration voltage and different magnifications: (a) 50000x, (b) 25000x, (c) 10000x, (d) 5000x, (e) 2000x, (f) 1000x. 


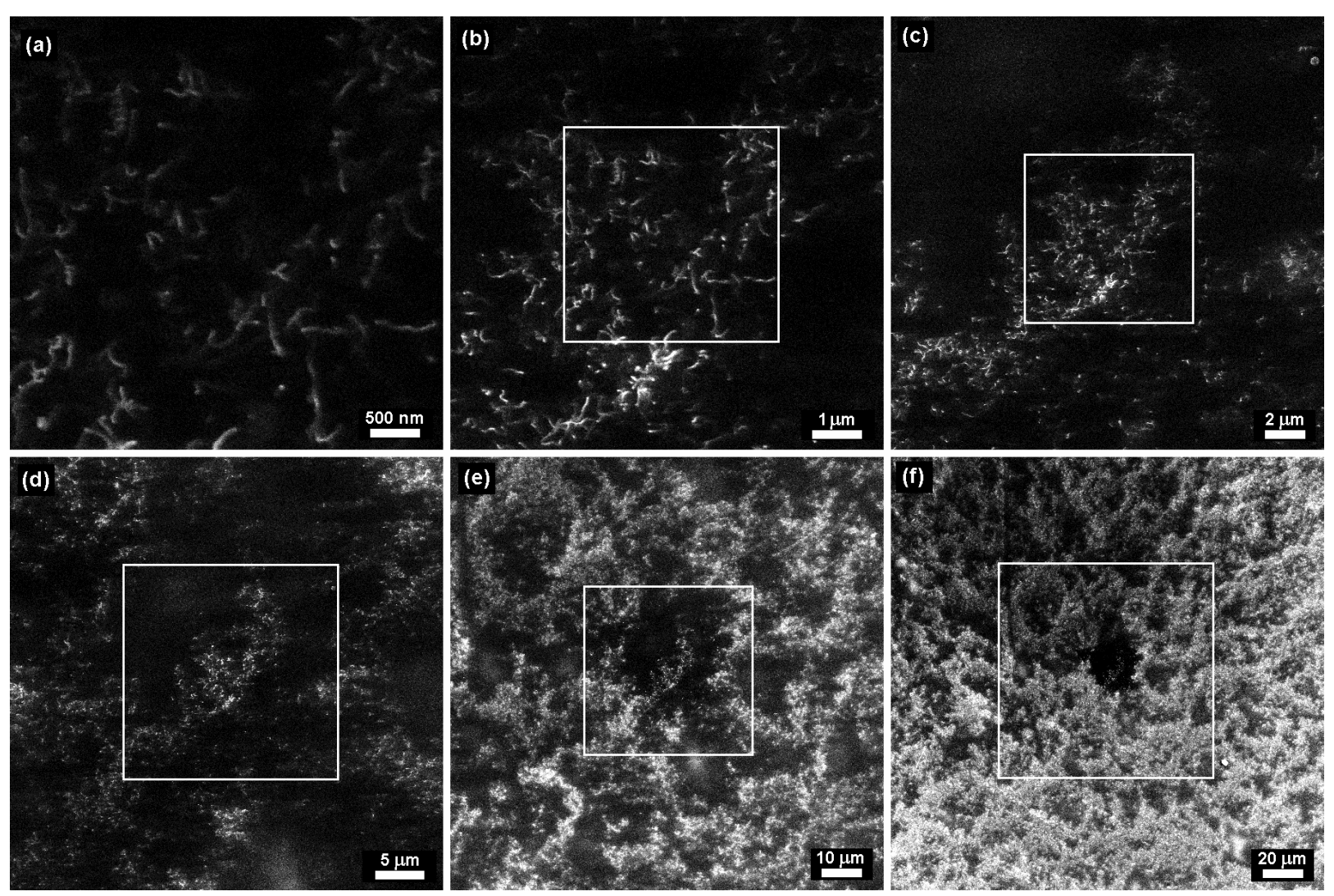

Fig. 3. Spin-coated composite (26 $\mu \mathrm{m}$ film thickness) containing 1 wt\% MWCNTs in E20 resin recorded at $20 \mathrm{kV}$ acceleration voltage and different magnifications: (a) 50000x, (b) 25000x, (c) 10000x, (d) 5000x, (e) 2000x, (f) 1000x.

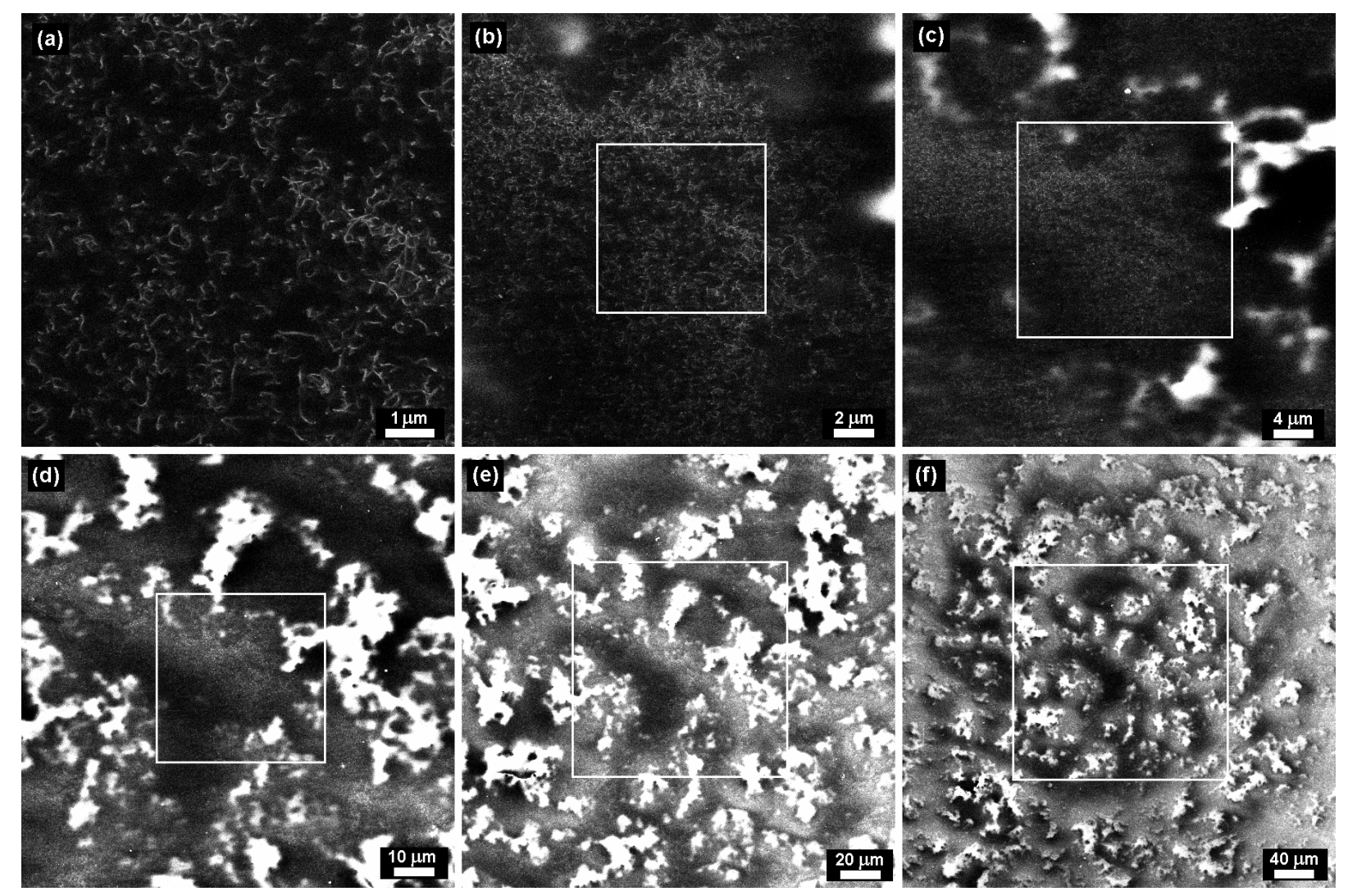

Fig. 4. Spin-coated composite (20 $\mu \mathrm{m}$ film thickness) containing 1 wt\% MWCNTs in LY556 resin recorded at $10 \mathrm{kV}$ acceleration voltage and different magnifications: (a) 25000x, (b) 10000x, (c) 5000x, (d) 2000x, (e) $1000 x$, (f) $500 x$. 


\subsection{Dispersion quality analysis by means of voltage contrast images}

Three series of pictures recorded with the InLens detector are presented in Figs. 2 - 4 . They show zooming out sequences from high to low magnification without changing the scanning position on the three samples (the white squares denote the area of the preceding zoom step). The first sample displays a homogeneous and dense nanotube layer (Fig. 2) while the second and third ones exhibit close-meshed (Fig. 3) and widemeshed (Fig. 4) network structures (note that all pictures in Fig. 4 are shifted by one zooming step when compared to Fig. 2 and 3 ). It should be also noted that all nanotubes visible in Figs. $2-4$ are distributed within $\sim 50 \mathrm{~nm}$ of sample depth, which is much smaller than the sample thicknesses. The series point out a new way for analyzing the quality of nanotube dispersions over several length scales, from tens of nanometers to some hundred micrometers.

We can deduce from the comparison of the pictures in Figs. 3 and 4 that increased charging of the matrix and subsequent image whitening takes place in areas where the nanotube concentration drops below a certain level. The influence of these charged areas can increase substantially and thereby outshine the signal of the CNTs. In our case, imaging of nanotubes at high acceleration voltages was possible down to a CNT concentration of $0.5 \mathrm{wt} \%$ (corresponding to a conductivity of $\sim 10^{-2} \mathrm{~S} / \mathrm{m}$ ) for good dispersions. However, lower nanotube concentrations and poorly dispersed nanotubes can also be analyzed when low acceleration voltages are used, as will be reported in section 3.4 .

\subsection{The influence of SEM parameters on the voltage contrast}

Fig. 5 shows high magnification SEM images of the same sample recorded at different acceleration voltages. For low acceleration voltages $(0.2-0.7 \mathrm{kV})$ the nanotubes appear bright with a dark polymer. The contrast nearly vanishes around $0.7 \mathrm{kV}$ (not shown) and subsequently inverts displaying dark nanotubes with a bright polymer. It should be noted that the boundaries of contrast changing are not defined by the acceleration voltage only, as dark nanotubes are visible at $1 \mathrm{kV}$ and bright ones at $1.5 \mathrm{kV}$ too. Interestingly, the nanotubes start changing contrast from their edge to their center. The contrast reaches a maximum around $1.5 \mathrm{kV}$ and then starts decreasing again until it vanishes for a second time around $2 \mathrm{kV}$ (not shown), inverts and again reveals bright nanotubes with a dark polymer $(4-20 \mathrm{kV})$. Similar analyses were conducted on a fixed region of the sample but - unlike the results reported in [61] - no additional nanotubes appeared with increasing acceleration voltage. This is consistent with the SEM theory which indicates a maximum depth of SE emission of $\sim 50 \mathrm{~nm}$ for light element samples [57,76]. However, this value could be altered due to electric field enhanced SE emission if opposite charges are present inside and onto the sample $[76,77]$. 

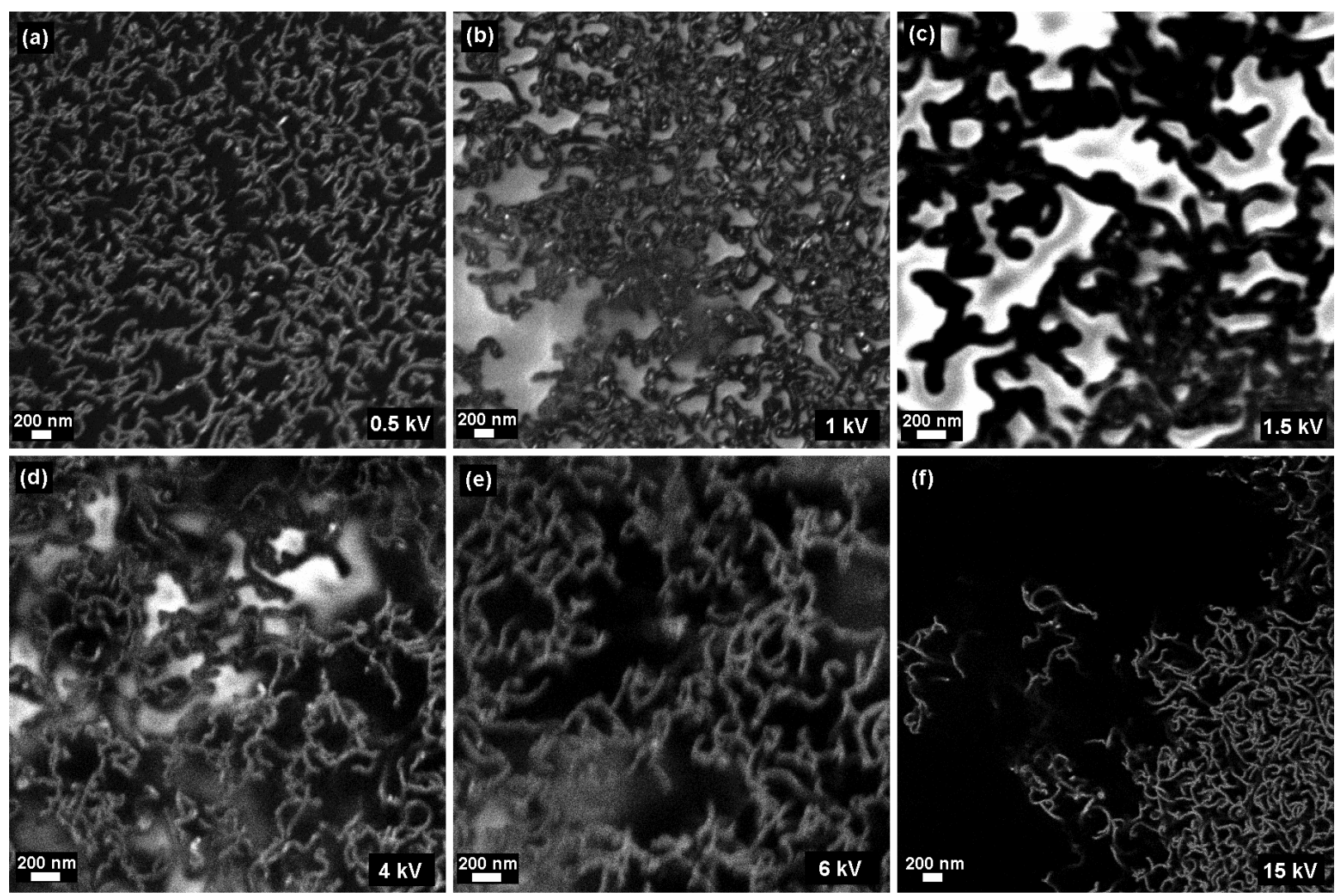

Fig. 5. The same sample as in Fig. 2 recorded at 25000 $\times$ magnification and different acceleration voltages: (a) $0.5 \mathrm{kV}$, (b) $1 \mathrm{kV}$, (c) $1.5 \mathrm{kV}$, (d) $4 \mathrm{kV}$, (e) $6 \mathrm{kV}$, (f) $15 \mathrm{kV}$.

In fact, Fig. 5 also visualizes another important feature of SEM. The charging of the sample by the incident electron beam - which in the end produces the voltage contrast needed for imaging - can be manipulated through the acceleration voltage. The total electron emission yield of a sample is depending on the beam energy and can even increase above unity [58]. This means that a sample can be charged positively or negatively or can remain uncharged if a proper acceleration voltage is chosen. For low acceleration voltages the total electron emission yield is smaller than unity, meaning the sample charges negative. Increasing the beam energy increases also the emission yield, which crosses unity at $E_{1}$ (generally below $1 \mathrm{keV}$ ) and starts charging the sample positive. In this energy region, the incident electrons excite efficiently many SE near the surface which then can all leave the sample. With increasing energy most SE are excited deeper and can no longer leave the sample. Hence, the emission yield starts to decrease, crosses unity at $E_{2}$ (generally $0.5-2 \mathrm{keV}$ for light element materials) and now charges the sample negative again. The acceleration voltages, where contrast is lost in our work, are in the right regions to be assigned to $E_{1}(=0.7 \mathrm{keV})$ and $E_{2}(=2 \mathrm{keV})$, meaning that we obviously monitored negative sample charging (below $E_{1}$ ), positive charging (between $E_{1}$ und $E_{2}$ ) and again negative charging (above $E_{2}$ ) in Fig. 5.

The explanation given above is based on analyses of electric field interactions between sample surface charges and ET detectors, which were conducted decades ago and do not necessarily apply to our InLens detector. Furthermore, sample charging must be understood in terms of relative charge densities, which are affected by additional 
parameters. The equilibrium density of charges depends on the relationship of the electron dose to the discharging capability of individual sample regions [58]. The dose itself depends on the scanning density (magnification) and scanning speed (beam dwell time per area).
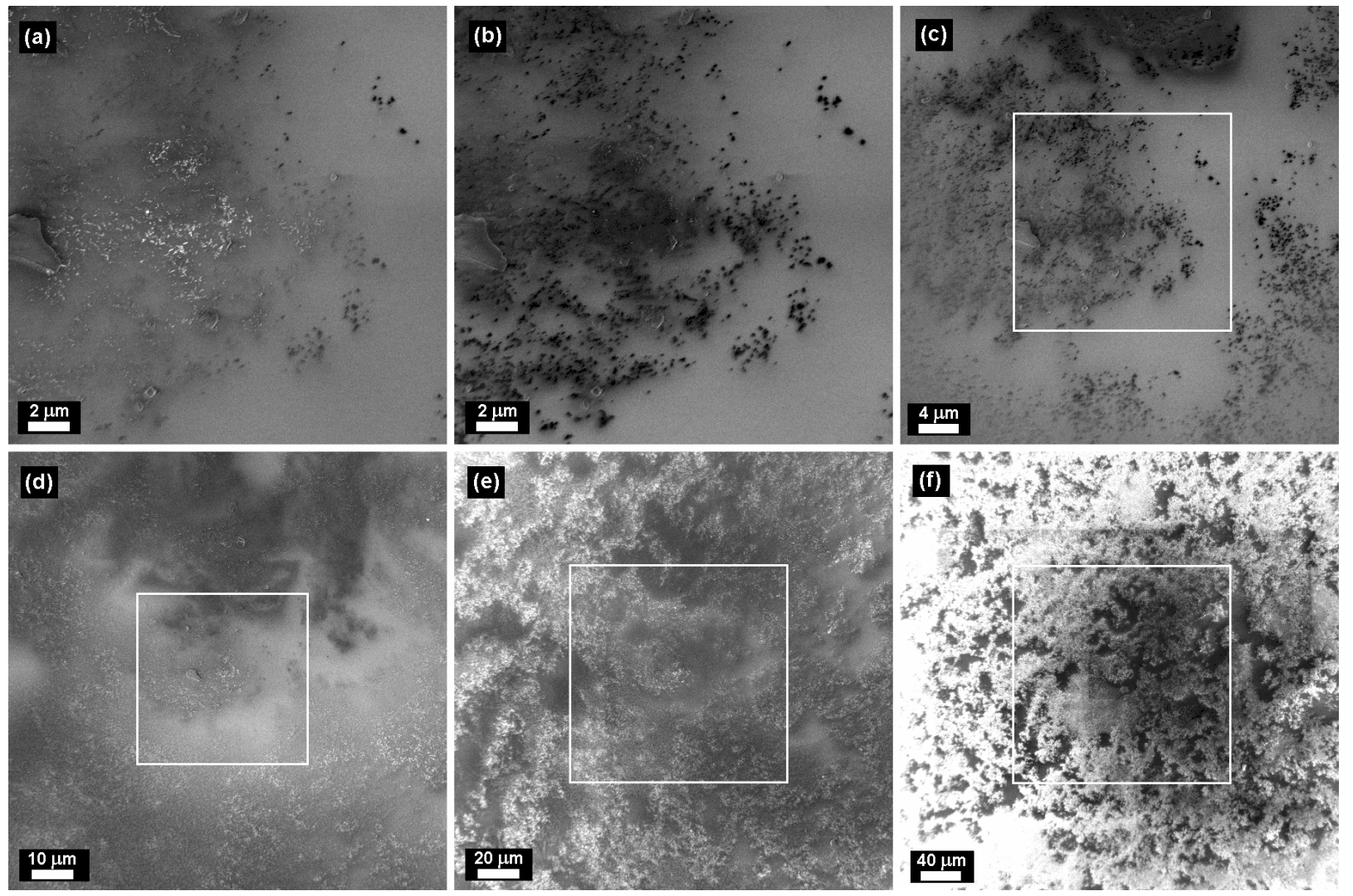

Fig. 6. The first (a) and third (b-f) scans of a spin-coated composite (10 $\mu \mathrm{m}$ film thickness) containing 1 wt\% MWCNTs in LY556 resin recorded at $0.5 \mathrm{kV}$ acceleration voltage and various magnifications: $(a, b)$ $10000 x$, (c) 5000x, (d) 2000x, (e) 1000x, (f) 500x.
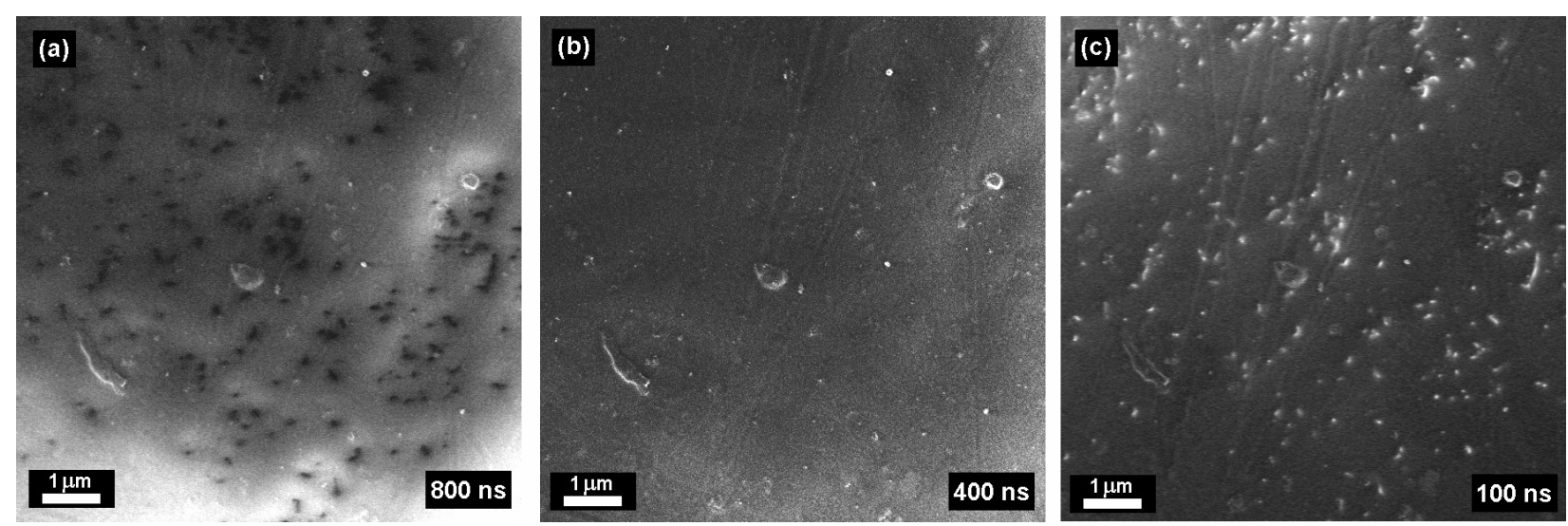

Fig. 7. The same sample as in Fig. 3 recorded at $0.6 \mathrm{kV}$ acceleration voltage, $25000 \times$ magnification and different beam dwell times: (a) $800 \mathrm{~ns}$, (b) $400 \mathrm{~ns}$, (c) $100 \mathrm{~ns}$.

These dependencies are visualized in Figs. 6 and 7 using low acceleration voltages. The first scan of a sample at $0.5 \mathrm{kV}$ acceleration voltage leads to bright nanotubes (Fig. 6a), while scanning the same area several times turns the CNTs into dark ones (Fig. 6b). With increasing scanning speed ( 2 sec/frame) the nanotubes immediately appear 
bright again (not shown). The same effect is observed when zooming out from this region, even though we now scanned slowly and multiple times again (Fig. 6c-f). Similarly, Fig. 7 shows that a long beam dwell time yields dark CNTs while a short time leads to bright ones. Here, the frame scanning speed (e.g. $800 \mathrm{~ns} \times 1024 \times 768=630$ $\mu \mathrm{s})$ was much shorter than in the other experiments, so that multiple frames were integrated in order to get a total scanning time of $\sim 20 \mathrm{sec}$. This contrast reversal is encountered only when scanning (a) regions of poor CNT homogeneity or too low overall CNT concentration ( $<0.5 \mathrm{wt} \%)$ (b) at high magnifications and low acceleration voltages $(<1 \mathrm{kV})$. This clearly demonstrates the sensitivity of the charge density distribution on the electron dose. It should be noted that scanning the sample in Fig. 6 at high acceleration voltages $(\sim 10 \mathrm{kV})$ yields - for each magnification - images similar to the ones presented in Fig. 4.

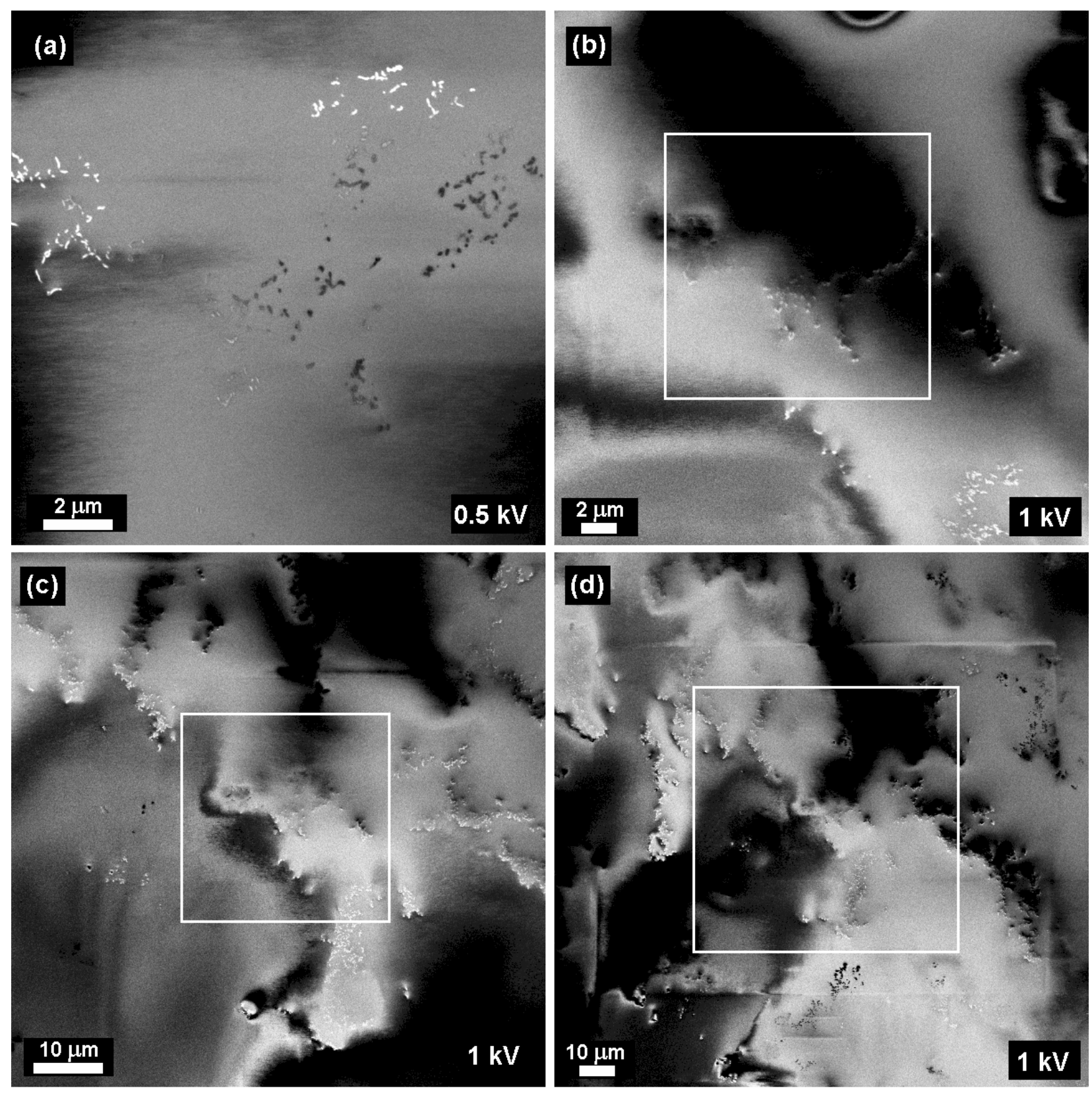

Fig. 8. Spin-coated composite (8 $\mu \mathrm{m}$ film thickness) containing $0.1 \mathrm{wt} \%$ MWCNTs in E20 resin recorded at different magnifications: (a) 10000x, (b) 5000x, (c) 2000x, (d) 1000x. 


\subsection{The potential of SEM analysis of nanotubes inside polymers}

Poorly conductive samples or regions can also be analyzed with SEM if low acceleration voltages are used. Gojny et al. [68] recently demonstrated this by recording high magnification images of nanotubes in a $0.1 \mathrm{wt} \%$ composite. High and low magnification SEM images of a spin-coated film with the same CNT concentration are displayed in Fig. 8. The nanotubes change their appearance from bright to dark within a single scan (Fig. 8a) which illustrates again the complexity of the charging mechanism. In the subsequent zooming out steps (Fig. 8b-d) large, dark areas of charging artifacts appear. Nevertheless, most nanotubes remain visible - mainly as bright dots - so that their macroscopic distribution can be monitored even for this low filler concentrations.
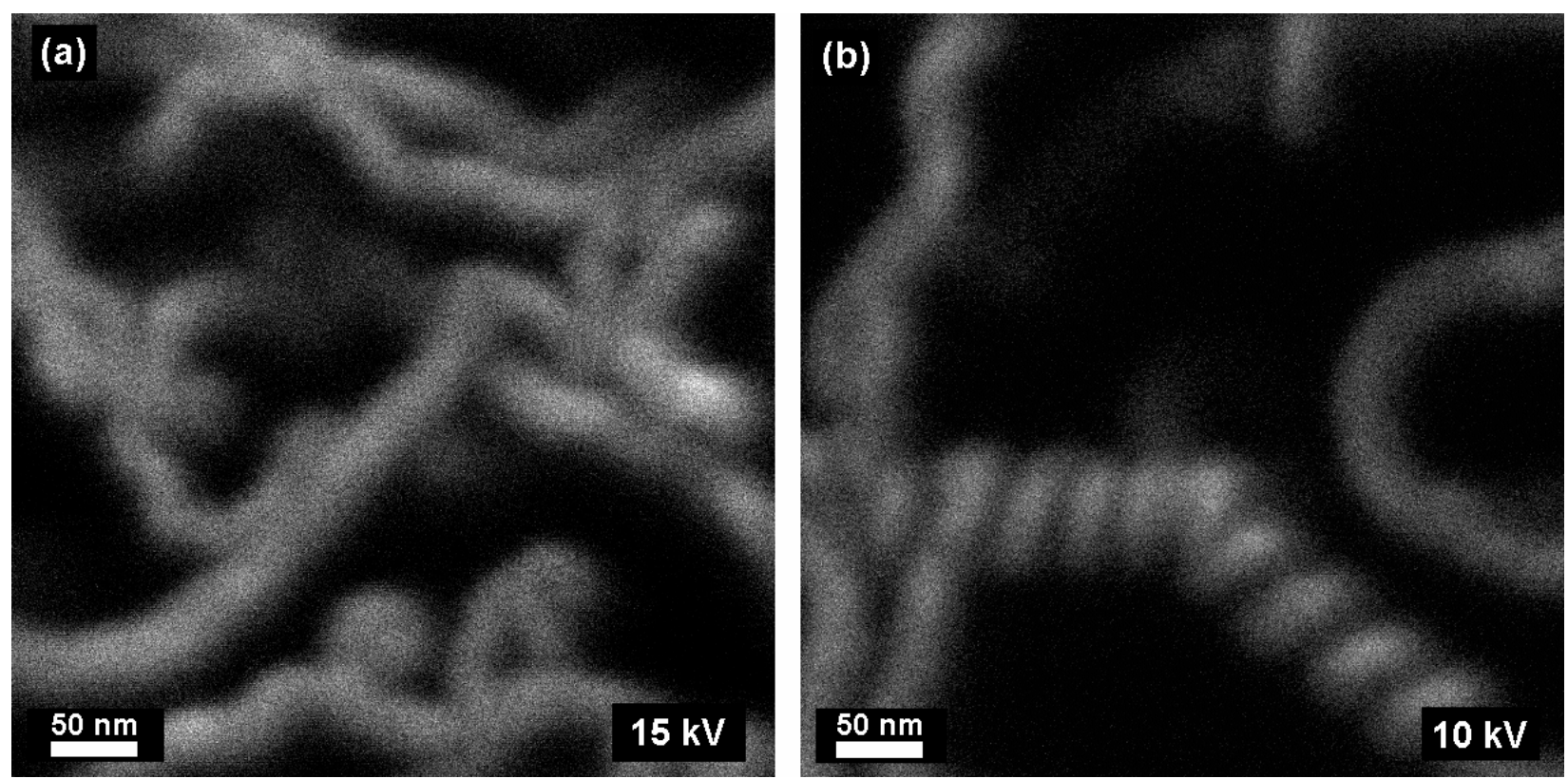

Fig. 9. Individual nanotubes inside a spin-coated composite (same sample as in Fig. 2) visualized at an extremely high magnification (500,000x) and an acceleration voltage of (a) $15 \mathrm{kV}$, (b) $10 \mathrm{kV}$.

Fig. 9 demonstrates the capability of an InLens detector of resolving individual nanotubes at magnifications usually encountered in a transmission electron microscope (TEM) analysis. The observed structures are individual nanotubes with their initial diameter ( $15 \mathrm{~nm}$ ) approximately doubled by charging effects. The nanotubes appear to be curly and entangled (Fig. 9a) as expected due to the large-scale production CCVDtechnique and even exhibit amazing coil spring-like structures (Fig. 9b). We want to point out that such high magnifications introduce an immense dose into the sample leading - in our case - to irreversible damaging (whitening of the whole area) within two slow scans (20 sec/frame).

\section{Conclusions}

The technique of nanotube visualization inside polymers with SEM was discussed in detail in order to enable the analysis of filler distributions inside polymers at several 
length scales. The key for this task seems to be (a) the detection of secondary electrons $\left(\mathrm{SE}_{1}\right)$ excited in the electron beam impact area and (b) the use of an appropriate detector which is sensitive to slight charges on sample surfaces. The quality of filler particle dispersion can be monitored accurately at high acceleration voltages ( 10 kV) when the sample conductivity is at least $10^{-2} \mathrm{~S} / \mathrm{m}$ (thus, $0.5 \mathrm{wt} \%$ nanotubes in our case) and at low voltages $(0.5-1 \mathrm{kV})$ even for lower conductivities.

SEM pictures of CNTs in insulating matrices were taken by exploiting the voltage (or charge) contrast. The effect of several parameters (such as magnification, scanning speed, acceleration voltage, sample conductivity and dispersion quality) on the voltage contrast were investigated. Our results show that increasing the acceleration voltage does not increase the nanotube sampling depth. Secondary electrons have energies up to $50 \mathrm{eV}$ and can only leave the sample when excited within a depth of $\sim 50 \mathrm{~nm}$, thus, only limited information about the three-dimensional organization of CNTs in a matrix can be obtained.

\section{Acknowledgements}

The authors wish to thank Dr. Heiner Jaksch of Carl Zeiss Inc. (Oberkochen, Germany), Peter T. Lillehei of NASA Langley Research Center (Hampton, USA) and Dr. Florian Gojny and Malte Wichmann of Institut für Kunststoffe und Verbundwerkstoffe (TUHH), for valuable discussions.

[1] Davis WR, Slawson RJ, Rigby GR. An unusual form of carbon. Nature 1953;171:756.

[2] Oberlin A, Endo M. Filamentous growth of carbon through benzene decomposition. J Cryst Growth 1976;32:335-49.

[3] Nesterenko AM, Kolesnik NF, Akhmatov YS, Sukhomlin VI, Prilutski OV. Metals 3 UDK 869.173.23. News of the Academy of Science, USSR;1982, p.12-6.

[4] lijima S. Helical microtubules of graphitic carbon. Nature 1991;354:56-8.

[5] Sandler J, Shaffer MSP, Prasse T, Bauhofer W, Schulte K, Windle AH. Development of a dispersion process for carbon nanotubes in an epoxy matrix and the resulting electrical properties. Polymer 1999;40(21):5967-71.

[6] Haggenmueller R, Gommans HH, Rinzler AG, Fischer JE, Winey KI. Aligned single-wall carbon nanotubes in composites by melt processing methods. Chem Phys Lett 2000;330(3-4):219-25.

[7] Andrews $R$, Jacques $D$, Minot $M$, Rantell T. Fabrication of carbon multiwall nanotube/polymer composites by shear mixing. Macromol Mater Eng 2002;287(6):395-403.

[8] Allaoui A, Bai S, Cheng HM, Bai JB. Mechanical and electrical properties of a MWNT/epoxy composite. Compos Sci Technol2002;62(15):1993-98.

[9] Safadi B, Andrews R, Grulke EA. Multiwalled carbon nanotube polymer composites: Synthesis and characterization of thin films. J Appl Polym Sci 2002;84(14):2660-69.

[10] Hobbie EK, Wang H, Kim H, Lin-Gibson S, Grulke EA. Orientation of carbon nanotubes in a sheared polymer melt. Phys of Fluids 2003;15(5):1196-203. 
[11] Du F, Fischer JE, Winey KI. Coagulation Method for Preparing Single-Walled Carbon Nanotube/Poly (methyl methacrylate) Composites and Their Modulus, Electrical Conductivity, and Thermal Stability. J Polym Sci B 2003;41(24):3333-8.

[12] Du FM, Scogna RC, Zhou W, Brand S, Fischer JE, Winey KI. Nanotube networks in polymer nanocomposites: Rheology and electrical conductivity. Macromol 2004;37(24):9048-55.

[13] Martin CA, Sandler JKW, Shaffer MSP, Schwarz MK, Bauhofer W, Schulte K, et al. Formation of percolating networks in multi-wall carbon-nanotube-epoxy composites. Compos Sci Technol 2004;64(15):2309-16.

[14] Kashiwagi T, Du FM, Winey KI, Groth KA, Shields JR, Bellayer SP, et al. Flammability properties of polymer nanocomposites with single-walled carbon nanotubes: effects of nanotube dispersion and concentration. Polymer 2005;46(2):471-8.

[15] Martin CA, Sandler JKW, Windle AH, Schwarz MK, Bauhofer W, Schulte K, et al. Electric fieldinduced aligned multi-wall carbon nanotube networks in epoxy composites. Polymer 2005;46(3):877-86.

[16] Brown JM, Anderson DP, Justice RS, Lafdi K, Belfor M, Strong KL, et al. Hierarchical morphology of carbon single-walled nanotubes during sonication in an aliphatic diamine. Polymer 2005;46(24):10854-65.

[17] Inam F, Peijs T. Transmission light microscopy of carbon nanotubes-epoxy nanocomposites involving different dispersion methods. Adv Compos Lett 2006;15(1):7-13.

[18] Kovacs JZ, Velagala BS, Schulte K, Bauhofer W. Two percolation thresholds in carbon nanotube epoxy composites. Compos Sci Technol 2007;67(5):922-8.

[19] Pecastaings G, Delhaes P, Derre A, Saadaoui H, Carmona F, Cui S. Role of interfacial effects in carbon nanotube/epoxy nanocomposite behaviour. J Nanosci Nanotechnol 2004;4(7):838-43.

[20] McNally T, Pötschke P, Halley P, Murphy M, Martin D, Bell SEJ, et al. Polyethylene multiwalled carbon nanotube composites. Polymer 2005;46(19):8222-32.

[21] Xu XJ, Thwe MM, Shearwood C, Liao K. Mechanical properties and interfacial characteristics of carbon-nanotube-reinforced epoxy thin films. Appl Phys Lett 2002;81(15):2833-5.

[22] Dufresne A, Paillet M, Putaux JL, Canet R, Carmona F, Delhaes $P$, et al. Processing and characterization of carbon nanotube/poly(styrene-co-butyl acrylate) nanocomposites. J Mater Sci 2002;37(18):3915-23.

[23] Pötschke P, Fornes TD, Paul DR. Rheological behavior of multiwalled carbon nanotube/polycarbonate composites. Polymer 2002;43(11):3247-55.

[24] Sandler JKW, Kirk JE, Kinloch IA, Shaffer MSP, Windle AH. Ultra-low electrical percolation threshold in carbon-nanotube-epoxy composites. Polymer 2003;44(19):5893-99.

[25] Courty S, Mine J, Tajbakhsh AR, Terentjev EM. Nematic elastomers with aligned carbon nanotubes: New electromechanical actuators. Europhys Lett 2003;64(5):654-60.

[26] Watts PCP, Ponnampalam DR, Hsu WK, Barnes A, Chambers B. The complex permittivity of multiwalled carbon nanotube-polystyrene composite fims in X-band. Chem Phys Lett 2003;378(5-6):609-14.

[27] Ramasubramaniam R, Chen J, Liu H. Homogeneous carbon nanotube/polymer composites for electrical applications. Appl Phys Lett 2003;83(14):2928-30.

[28] Koerner H, Price G, Pearce NA, Alexander M, Vaia RA. Remotely actuated polymer nanocomposites - stress-recovery of carbon-nanotube-filled thermoplastic elastomers. Nature Mater 2004;3(2):115-20.

[29] Li X, Gao H, Scrivens VA, Fei D, Xu X, Sutton MA, et al. Nanomechanical characterization of singlewalled carbon nanotube reinforced epoxy composites. Nanotechnol 2004;15(11):1416-23.

[30] Lau KT, Lu M, Lam CK, Cheung HY, Sheng FL, Li HL. Thermal and mechanical properties of singlewalled carbon nanotube bundle-reinforced epoxy nanocomposites: the role of solvent for nanotube dispersion. Compos Sci Technol 2005;65(5):719-25.

[31] Liu LQ, Wagner HD. Rubbery and glassy epoxy resins reinforced with carbon nanotubes. Compos Sci Technol 2005;65(11-12):1861-8.

[32] Song YS, Youn JR. Influence of dispersion states of carbon nanotubes on physical properties of epoxy nanocomposites. Carbon 2005;43(7):1378-85.

[33] Koerner H, Liu WD, Alexander M, Mirau P, Dowty H, Vaia RA. Deformation-morphology correlations in electrically conductive carbon nanotube thermoplastic polyurethane nanocomposites. Polymer 2005;46(12):4405-20. 
[34] Xiao K, Zhang L. Effective separation and alignment of long entangled carbon nanotubes in epoxy. J Mater Sci 2005;40(24):6513-16.

[35] Aarab H, Baitoul M, Wery J, Almairac R, Lefrant S, Faulques E, et al. Electrical and optical properties of PPV and single-walled carbon nanotubes composite films. Synth Met 2005;155(1):63-7.

[36] Bryning MB, Islam MF, Kikkawa JM, Yodh AG. Very low conductivity threshold in bulk isotropic singlewalled carbon nanotube-epoxy composites. Adv Mater 2005;17(9):1186-91.

[37] Kim YA, Hayashi T, Endo M, Gotoh Y, Wada N, Seiyama J. Fabrication of aligned carbon nanotubefilled rubber composite. Scripta Mater 2006;54(1):31-5.

[38] Dalmas F, Dendievel R, Chazeau L, Cavaille JY, Gauthier C. Carbon nanotube-filled polymer composites. Numerical simulation of electrical conductivity in three-dimensional entangled fibrous networks. Acta Mater 2006;54(11):2923-31.

[39] Zhu BK, Xie SH, Xu ZK, Xu YY. Preparation and properties of the polyimide/multi-walled carbon nanotubes (MWNTs) nanocomposites. Compos Sci Technol 2006;66(3-4):548-54.

[40] Kueseng K, Jacob KI. Natural rubber nanocomposites with SiC nanoparticles and carbon nanotubes. Europ Polym J 2006;42(1):220-7.

[41] Zhu J, Kim JD, Peng HQ, Margrave JL, Khabashesku VN, Barrera EV. Improving the dispersion and integration of single-walled carbon nanotubes in epoxy composites through functionalization. Nano Lett 2003;3(8): 1107-13.

[42] Cooper CA, Ravicha D, Lips D, Mayer J, Wagner HD. Distribution and alignment of carbon nanotubes and nanofibrils in a polymer matrix. Compos Sci Technol 2002;62(7-8):1105-12.

[43] Park C, Ounaies Z, Watson KA, Crooks RE, Smith J, Lowther SE, et al. Dispersion of single wall carbon nanotubes by in situ polymerization under sonication. Chem Phys Lett 2002;364(3-4):303-8.

[44] Lin Y, Zhou B, Fernando KAS, Liu P, Allard LF, Sun YP. Polymeric carbon nanocomposites from carbon nanotubes functionalized with matrix polymer. Macromol 2003;36(19):7199-204.

[45] Pötschke P, Bhattacharyya AR, Janke A. Carbon nanotube-filled polycarbonate composites produced by melt mixing and their use in blends with polyethylene. Carbon 2004;42(5-6):965-9.

[46] Seo MK, Park SJ. Electrical resistivity and rheological behaviors of carbon nanotubes-filled polypropylene composites. Chem Phys Lett 2004;395(1-3):44-8.

[47] Meincke O, Kaempfer D, Weickmann H, Friedrich C, Vathauer M, Warth H. Mechanical properties and electrical conductivity of carbon-nanotube filled polyamide- 6 and its blends with acrylonitrile/butadiene/styrene. Polymer 2004;45(3):739-48.

[48] Grunlan JC, Mehrabi AR, Bannon MV, Bahr JL. Water-based single-walled-nanotube-filled polymer composite with an exceptionally low percolation threshold. Adv Mater 2004;16(2):150-3.

[49] Dalmas F, Chazeau L, Gauthier C, Masenelli-Varlot K, Dendievel R, Cavaille JY, et al. Multiwalled carbon nanotube/polymer nanocomposites: Processing and properties. J Polym Sci B 2005;43(10):118697.

[50] Fan ZH, Advani SG. Characterization of orientation state of carbon nanotubes in shear flow. Polymer 2005;46(14):5232-40.

[51] Gojny FH, Wichmann MHG, Fiedler B, Schulte K. Influence of different carbon nanotubes on the mechanical properties of epoxy matrix composites - A comparative study. Compos Sci Technol 2005;65(15-16):2300-13.

[52] Chen W, Tao XM. Production and characterization of polymer nanocomposite with aligned single wall carbon nanotubes. Appl Surf Sci 2006;252(10):3547-52.

[53] Hu GJ, Zhao CG, Zhang SM, Yang MS, Wang ZG. Low percolation thresholds of electrical conductivity and rheology in poly(ethylene terephthalate) through the networks of multi-walled carbon nanotubes. Polymer 2006;47(1):480-8.

[54] Dalmas F, Chazeau L, Gauthier C, Cavaillé JV, Dendievel R. Large deformation mechanical behavior of flexible nanofiber filled polymer nanocomposites. Polymer 2006;47(8):2802-12.

[55] Xia HS, Qiu GH, Wang Q. Polymer/carbon nanotube composite emulsion prepared through ultrasonically assisted in situ emulsion polymerization. J Appl Polym Sci 2006;100(4):3123-30.

[56] Lee KC, Yu HH, Hwang SJ, Li YS, Cheng MH, Lin CC. Preparation and characterization of the modified carbon nanotubes enhanced epoxy resin composites. Mater Sci Forum 2006;505:1075-80. 
[57] Goldstein J, Newbury D, Joy D, Lyman C, Echlin P, Lifshin E, et al. Scanning Electron Microscopy and X-Ray Microanalysis, 3rd ed. New York: Kluwer Academic / Plenum Publishers, 2003.

[58] Reimer L. Scanning Electron Microscopy, 2nd ed. Berlin: Springer-Verlag, 1998.

[59] Oatley CW, Everhart TE. The examination of $p-n$ junctions with the SEM. J Electronics 1957;2(6):568-70.

[60] Chung KT, Reisner JH, Campbell ER. Charging phenomena in the scanning electron microscopy of conductor-insulator composites: A tool for composite structural analysis. J Appl Phys 1983;54(11):6099112.

[61] Loos J, Alexeev A, Grossiord N, Koning CE, Regev O. Visualization of single-wall carbon nanotube (SWNT) networks in conductive polystyrene nanocomposites by charge contrast imaging. Ultramicroscopy 2005;104(2):160-7.

[62] Lillehei PT, Kim JW, Park C, Crooks RE, Siochi EJ. Optical, Electron and Probe Microscopy Characterization of Carbon Nanotube Composites. NIST Practice Guide: Measurement Issues in Single Wall Carbon Nanotubes (Draft), December 31, 2005, http://www.msel.nist.gov/Nanotube2/Carbon_Nanotubes_Guide.htm

[63] Watts PCP, Hsu WK, Randall DP, Kroto HW, Walton DRM. Non-linear current-voltage characteristics of electrically conducting carbon nanotube-polystyrene composites. Phys Chem, Chem Phys 2002;4(22):5655-62.

[64] Smith JG, Connell JW, Delozier DM, Lillehei PT, Watson KA, Lin Y, et al. Space durable polymer/carbon nanotube films for electrostatic charge mitigation. Polymer 2004;45(3):825-36.

[65] Smith JG, Delozier DM, Connell JW, Watson KA. Carbon nanotube-conductive additive-space durable polymer nanocomposite films for electrostatic charge dissipation. Polymer 2004;45(18):6133-42.

[66] Regev O, ElKati PNB, Loos J, Koning CE. Preparation of conductive nanotube-polymer composites using latex technology. Adv Mater 2004;16(3):248-51.

[67] Kim YJ, Shin TS, Choi HD, Kwon JH, Chung YC, Yoon HG. Electrical conductivity of chemically modified multiwalled carbon nanotube/epoxy composites. Carbon 2005;43(1):23-30.

[68] Gojny FH, Wichmann MHG, Fiedler B, Kinloch IA, Bauhofer W, Windle AH, et al. Evaluation and identification of electrical and thermal conduction mechanisms in carbon nanotube/epoxy composites. Polymer 2006;47(6):2036-45.

[69] Cao Q, Hur SH, Zhu ZT, Sun Y, Wang CJ, Meitl MA, et al. Highly bendable, transparent thin-film transistors that use carbon-nanotube-based conductors and semiconductors with elastomeric dielectrics. Adv Mater 2006;18(3):304-9.

[70] Park C, Wilkinson J, Banda S, Ounaies Z, Wise KE, Sauti G, et al. Aligned single-wall carbon nanotube polymer composites using an electric field. J Polym Sci B 2006;44(12):1751-62.

[71] Gojny FH, Wichmann MHG, Köpke U, Fiedler B, Schulte K. Carbon nanotube-reinforced epoxycomposites: enhanced stiffness and fracture toughness at low nanotube content. Compos Sci Technol 2004;64(15):2363-71.

[72] Jaksch H, Martin JP. High-resolution, low-voltage SEM for true surface imaging and analysis. Fresenius' J Analyt Chem 1995;353(3-4):378-82.

[73] Jaksch H. Neues Konzept für ein hochauflösendes Niederspannungs-Schottky-FE-SEM. Chemie in Labor und Biotechnik 1996;10:452-6.

[74] Dotan N. A Method for Enhancing Topography and Material Contrast in Automatic SEM Review. Metrology, inspection, and process control for microlithography XIII. Santa Clara (California, USA): SPIE, 1999; 3677:491-8.

[75] Cazaux J. About the role of the various types of secondary electrons (SE1; SE2; SE3) on the performance of LVSEM. J Microscopy 2004;214(3):341-7.

[76] Seiler H. Einige aktuelle Probleme der Sekundärelektronenemission. Zeitschrift für Angewandte Physik 1967;22(3):249-63.

[77] Nelson H. Field-Enhanced Secondary Electron Emission. Phys Rev 1940;57:560. 